Dissertation

\title{
Conflict and Order in the Global Project Organization
}

\author{
Rachel Pacheco ${ }^{1}$ a \\ 1 The Wharton School, University of Pennsylvania, USA \\ Keywords: project organization, megaprojects, stakeholder, intraorganizational conflict \\ https://doi.org/10.46697/001c.30066
}

\section{AIB Insights}

Vol. 21, Issue 4, 2021

\begin{abstract}
The global project organization is a group of firms that comes together to complete a goal, such as the building of a bridge, the construction of a power plant, or the development of a new technology. These project organizations are complex as multiple firms with different operating norms, backgrounds, and organizational cultures coordinate and collaborate to avoid harmful conflict. Additionally, these project organizations navigate complex external environments as governments, local labor groups, and other stakeholders are often involved and impacted by project organization's operations. In this research, I examine how the structure of the project organization, specifically how the concentration of power affects conflict and ultimately performance.
\end{abstract}

\section{BIG QUESTION}

How do complex organizations navigate the complex environments in which they operate, and navigate conflict amongst their partners and external stakeholders?

\section{RESEARCH SUMMARY}

Large global projects, such as those focused on building a bridge, developing and delivering a vaccine, or constructing a highway, are complex, lengthy, expensive, and often closely involve government and other local and national players given the economic and strategic importance of these projects to communities and countries. Multi-national companies, local contractors, as well as non-government organizations come together to form project organizations that execute on these projects, and then disband once the project is completed. External stakeholders, such as labor groups, government officials, and community members also are closely involved in the approval, acceptance, and delivery of these projects. As seen acutely in two examples illustrated below, conflict between members of the project organization, and conflict aimed towards the project organization is not just possible, but also probable as multiple parties with differing goals, ways of working, and long-term objectives are involved.

In March of 2021, terrorist groups launched a deadly attack on a $\$ 20$ billion USD liquid natural gas project in the Cabo Delgado region of Mozambique. Total, the project owner, was forced to halt work on the project and evacuate its workers, and 11,000 civilians affected by the conflict fled

the region. The viability of the nearby projects of ExxonMobil, Chevron, BP, Mitsui, and Petronas was called into question given the most recent violence. The attack in March was not a surprise: since 2017 when investment into the region's liquid natural gas reserves began, a violent militant insurgency involving rebels, the local community, and the national army has resulted in 798 incidents of conflict with nearly 4,000 fatalities and over 600,000 refugees (World Bank, 2021). When investments in the impoverished Cabo Delgado region were first announced, funders, the government, and the project owners emphasized the employment, energy access, and other opportunities for the Mozambican people that would result from the influx of capital. However, reality, as reflected by the violence in March, did not seem to match these original expectations:

So far Total's operations fit a long-standing pattern of
wealth being extracted from the province with little
benefit to the people living there. What has been billed
as a bonanza of jobs and development for this neglected
region...may instead prove to be a catalyst for the mis-
ery and chaos that have accompanied so many other
extractive mega projects on the continent (Mongabay,
2021).

Another project, the Kerala State Transport Project, was a $\$ 336$ million project aimed at strengthening the road network of the Indian state of Kerala. Numerous organizations - including international and local firms - worked to complete the multi-year project, with the bulk of the road work being undertaken by a Malaysian-based company, PATI, and an Indian-based firm, Bhageeratha Engineering, Ltd. Yet, despite successful funding and planning on the front end,

a Ph.D. awarded by University of Pennsylvania, USA (May 2021)

Dissertation title: A Contingent Theory of Governance for the Global Project Organization: The Effect of Uncertainty and Diversity on Order and Conflict 
the project overran its initial timing and financial estimates and was plagued by corruption and nepotism. Contractors fought with local government officials who refused to hand over land required for the project. Local laborers clashed with the local and international companies over on-time salary payments. And partners from PATI and Bhageeratha repeatedly came into conflict because of their different operating norms. Besides time delays and financial loss, the project embarrassed the local and national governments, raised reputational issues for its primary funder, the World Bank, and sadly resulted in the fatality of the Malaysian project manager.

As seen in the Cabo Delgado and Kerala examples, project organizations contend with conflict between members of the project organization and between the project organization and stakeholders in the external environment, and often this conflict is detrimental to the project operations, and in some cases, damaging to the stakeholders and communities where the project is located. To reduce harmful conflict and ensure project success, members of the project organization build relationships with each other, build relationships with external stakeholders, and navigate an uncertain and often changing external environment. To be effective, members of the project organization coordinate and communicate, despite differing goals, functions, and cultural backgrounds. Collaborative mechanisms, a shared project culture, and informal relationship building are all important for reducing unproductive conflict amongst partners and ultimately benefiting the project's performance. Furthermore, because project organizations often operate without a singular formal authority, informal governance, specifically trust, is even more necessary for the project's success (Clegg, Pitsis, Rura-Polley, \& Marosszeky, 2002).

Additionally, the external environment poses challenges to the project organization. As seen in the Kerala State Transport example, members of the project organization navigate an external environment that is uncertain with regulations, policies, and institutions that are different from the members' home countries. Lastly, as seen in the Cabo Delgado example, the project organization also contends with a range of stakeholders - government officials, local labor groups, rebels, and community members. Thus, project organizations that effectively build relationships with local groups, develop trust, and secure the social license to operate in an environment may experience less conflict directed towards the project (Henisz, Dorobantu, \& Nartey, 2014).

Much research, especially in the construction management literature, has focused on what managers in these project organizations can do to ensure projects are successfully completed within the timeline and budget allocated. However, there remains an open question about the optimal structure for these projects, given the messiness inherent in multiple firms - with differing goals and objectives-coming together without a formal hierarchy. According to one school of thought, the optimal structure for navigating the internal and external challenges of the project organization is to have a "strong owner" - a firm that has a concentration of the project's resources (Winch \& Leiringer, 2016). This strong owner creates an informal hierarchy within the project organization, which in turn helps with efficient decision-making, coordination of members, and resolution of conflict if it is to occur. Yet others posit that this concentration of resources and power amongst a single or small group within the project organization instigates conflict. This other school of thought highlights that unequal access to resources promotes conflict and competition, as project members fight for limited resources, and push against the partners in control (Van Marrewijk, Ybema, Smits, Clegg, \& Pitsis, 2016).

In my research, I seek to better understand the tradeoffs in the strong owner model and develop recommendations for managers and funders of these project organizations (Pacheco, 2021). Using a dataset of 5,864 World Bank- sponsored projects comprised of over 100,000 partners that operate in 135 countries, I do not attempt to determine whether the strong owner, that is, a concentration of resources, is good or bad for the project organization: rather, I examine when and under what conditions relative differences in resources between partners and external stakeholders drive (or reduce) conflict and impact performance. I find that in some instances, as I outline below, the strong owner structure does indeed reduce conflict and help the project organization create shared operating norms. And I find that in other instances, the strong owner structure may harm the project organization and beyond, as it may drive conflict and competition between project members, and between external stakeholders surrounding the project. In examining the question of structure in the project organization, this research aims to provide practitioners with a better understanding of how to govern these large complex projects and reduce detrimental conflict, and what actions they can take to mitigate conflict once it does occur. My three primary findings are outlined below.

First, I examine how the concentration of financial resources of the project impacts conflict between members of the project organization, and conflict between the project organization and external stakeholders. Unlike past examinations of conflict that measure conflict as legal disputes, I examine conflict as disagreements between two or more parties that do not necessarily rise to a legal level. For example, two members of the project organization may have a disagreement on the timing of the project workplan, or the project organization as a whole may have a dispute with the local zoning authority over the timely hand over of land. Aligned with the view that unequal resources create competition, I find that the concentration of financial resources does indeed drive conflict experienced by the project organization. However, I also find that when the project organization is highly diverse, that is the members of the pro-

1 During the project, the Malaysian Chief Project Manager of PATI committed suicide; some believed it was due to his inability "to cope with the unorthodox ways of business in India.” http://indiatoday.intoday.in/story/engineer-lee-see-commits-suicide/1/180075.html 
ject organization are from a wide range of home countries, concentration of financial resources reduces conflict experienced by the project organization. I hypothesize that the strong owner may create a dominant set of operating norms by which all members of the project organization can subscribe to, thus reducing the friction and conflict that results from disparate norms of the diverse members. Additionally, I find that not all projects that experience high levels of conflict suffer from poor performance. Projects that have high levels of participatory mechanisms, shared decisionmaking, and other collaborative strategies throughout their life are buffered from the negative performance effects of conflict.

Second, I examine if the strong owner structure helps the project organization navigate uncertainty. I find that under conditions of environmental uncertainty - the risk that the external environment changes in an unknown way the strong owner structure may help. I posit that the informal hierarchy resulting from a strong owner allows the organization to better manage relationships with external stakeholders, especially in those environments where external stakeholders pose a threat to the organization's operations. I also posit that this structure helps the project organization collect, absorb, and share the knowledge that is required to navigate the unknown local context. I find that under conditions of behavioral uncertainty - that is, the risk partners will take advantage of each other - the relationship between uncertainty and hierarchy depends on the type of project. Some projects require more control and partner monitoring than others: I posit that for projects where there are not key performance indicators or strong industry-wide norms that help dictate behavior, strong ownership is helpful in managing behavioral uncertainty and ultimately leads to greater project performance.

Lastly, I examine how the project organization may be harmful to the environment in which it operates. The project organization may instigate conflict between external stakeholder groups, for example, between two different ethnic groups living in the same community where the project takes place or between two political parties. My coauthor and I hypothesize that the concentration of the networks of relationships surrounding the project organization impacts conflict between stakeholder groups. For project organizations that favor elites in their networks, that is, the project organization's relationships are concentrated to a small elite group, we posit that conflict arises because one group is privileged over another with the project's resources, as was seen in the Cabo Delgado example. We predict and find that the effect of elite bias on conflict is exacerbated in instances when the project organization is operating in an unknown external environment, as the project organization may not know the existing dynamics and fault lines amongst different external groups, as well as, in instances when non-competitive methods of procurement are used. Both instances heighten the perception and actual unequal allocation of resources to one group over another. For example, a project with a high elite bias that has members that were selected through non-competitive procurement means (essentially heightening the potential for favoritism and lack of procedural justice) has a higher likelihood of driving conflict amongst the stakeholders surrounding the project. Thus, these findings demonstrate that in certain instances, project organizations may be harmful to the environment in which they operate, and as such, have the opposite (and potentially violent) effect on the communities and countries they seek to help, as was seen in the Cabo Delgado example.

This research helps practitioners and managers of project organizations understand when a concentration of resources - whether those resources are financial or relational - drives conflict and reduces the performance of the project organization; and when this structure benefits the project organization. Additionally, this research shows that if conflict does occur, it need not ruin project performance: building participatory mechanisms and shared decisionmaking early in the life of the project may reduce the harm of conflict on project performance. Furthermore, I call attention to the risk of development projects - projects designed to reduce conflict and increase prosperity in a community - to have the opposite effect as intended. Development projects that favor elites, operate in unfamiliar contexts, and involve non-competitive selection processes may drive violent conflict amongst different stakeholder groups, as one stakeholder group may be privileged over another. It is critical that managers and practitioners fully understand the implications of this imbalanced allocation of resources - and develop tools such as community and trust building, investment in local institutions, and other actions to avoid and address the inequity these projects may create.

\section{ACKNOWLEDGEMENTS}

I would like to acknowledge Witold Henisz, Martine Haas, Sinziana Dorobantu, and Exequiel Hernandez for the support in this research. I would also like to acknowledge the Wharton Global Initiative, Wharton Social Impact Fund, Wharton Political Risk Lab and CIBER for support in this research.

\section{ABOUT THE AUTHOR}

Rachel Pacheco, PhD (rpacheco@wharton.upenn.edu), is a member of the teaching faculty at the Wharton School at the University of Pennsylvania where she teaches and conducts research on management. Specifically, Rachel's research interests lie in how power and conflict affect large project organizations around the world. Rachel received her $\mathrm{PhD}$ and MBA from the Wharton School and her BS from Georgetown University.

Submitted: August 16, 2021 EST, Accepted: November 23, 2021 EST 
This is an open-access article distributed under the terms of the Creative Commons Attribution 4.0 International License (CCBY-4.0). View this license's legal deed at http://creativecommons.org/licenses/by/4.0 and legal code at http://creativecommons.org/licenses/by/4.0/legalcode for more information. 


\section{REFERENCES}

Clegg, S. R., Pitsis, T. S., Rura-Polley, T., \& Marosszeky, M. 2002. Governmentality matters: Designing an alliance culture of inter-organizational collaboration for managing projects. Organization Studies, 23(3): 317-337.

Henisz, W. J., Dorobantu, S., \& Nartey, L. J. 2014. Spinning gold: The financial returns to stakeholder engagement. Strategic Management Journal, 35(12): $1727-1748$.

Mongabay. 2021. Gas fields and jihad: Mozambique's Cabo Delgado becomes a resource-rich war zone. htt ps://news.mongabay.com/2021/04/gas-fields-and-jiha d-mozambiques-cabo-delgado-becomes-a-resource-r ich-war-zone/.

Pacheco, R. 2021. A Contingent Theory of Governance for the Global Project Organization: The Effect of Uncertainty and Diversity on Order and Conflict. Unpublished PhD Dissertation, The Wharton School, University of Pennsylvania, Philadelphia, PA.
Van Marrewijk, A., Ybema, S., Smits, K., Clegg, S., \& Pitsis, T. 2016. Clash of the titans: Temporal organizing and collaborative dynamics in the Panama Canal megaproject. Organization Studies, 37(12): 1745-1769.

Winch, G., \& Leiringer, R. 2016. Owner project capabilities for infrastructure development: A review and development of the "strong owner" concept. International Journal of Project Management, 34(2): 271-281.

World Bank. 2021. The World Bank in Mozambique. https://www.worldbank.org/en/country/mozambique/ overview. 